This item is the archived peer-reviewed author-version of:

\title{
Rational synthesis of F-doped iron oxides on single crystals
}

\section{Reference:}

Carraro G., Gasparotto A., Maccato C., Bontempi E., Lebedev O.I., Sada C., Turner Stuart, van Tendeloo Gustaaf, Barreca D..Rational synthesis of F-doped iron oxides on single crystals

RSC advances - ISSN 2046-2069 - 94(2014), p. 52140-52146

Full text (Publishers DOI): http://dx.doi.org/doi:10.1039/C4RA09021G

Handle: http://hdl.handle.net/10067/1195290151162165141 


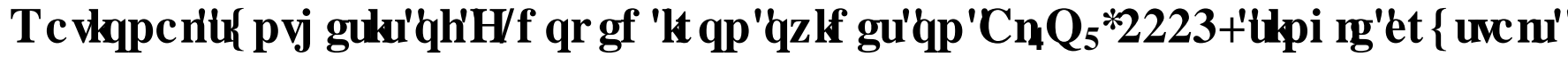

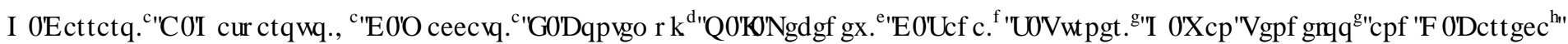

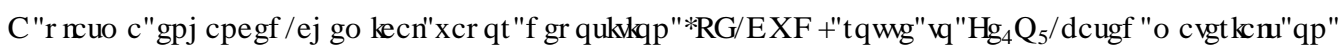

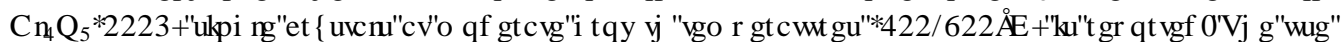

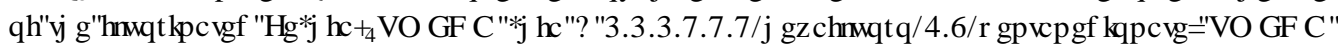

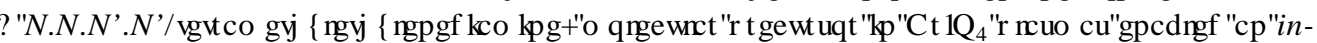

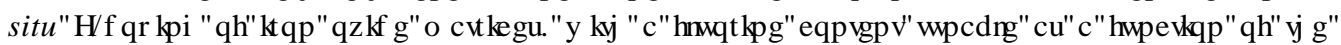

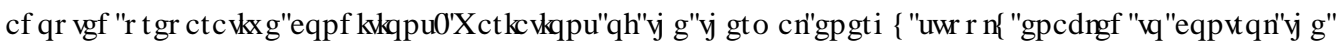

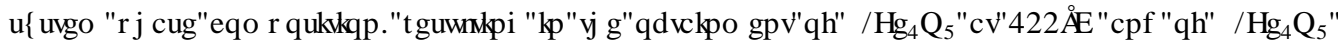

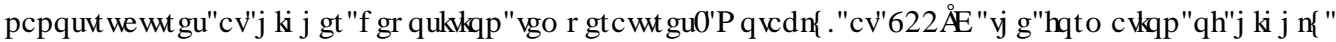

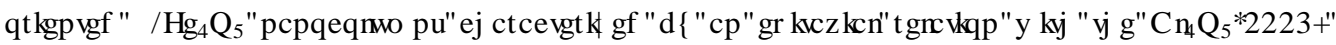
VXEWDM Z DV REYHYHGD \%HMGH IOXRUQH FRQMQWW SKDMH FRP SRYWRQ DQG QDQR]RU DQL DURQ]

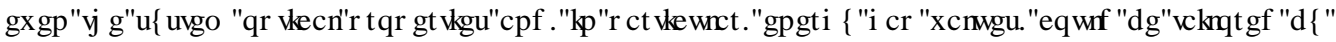
SLRSHUP RGIIFDMRQVIRIGSLRFHMQ ISDUP HMVI

\section{, QMRGXFWR}

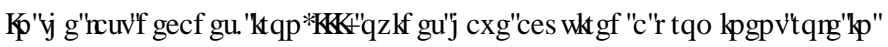

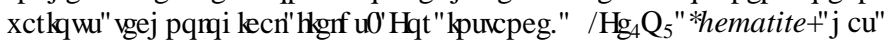
HP HJ HGDVDQRXWMOAD IHOFWRGHP DMUDDIRU* UHMHDFHOVDOG

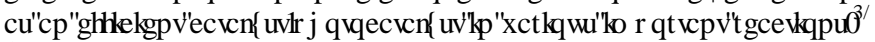

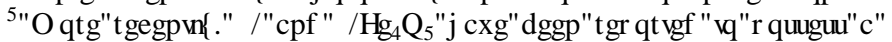

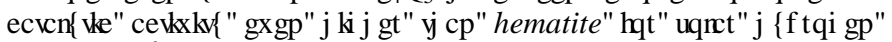

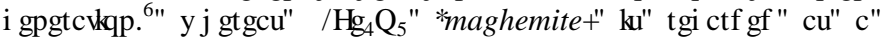
SLRP LMQ IP D QHMFP DMUDIQ SDWFXOUIRULWWSHSDUP D QHME EHWMIRU ${ }^{\square}$

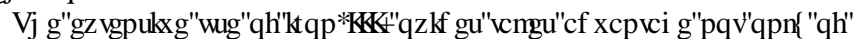

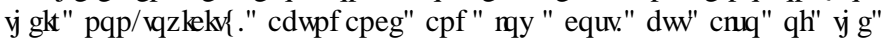

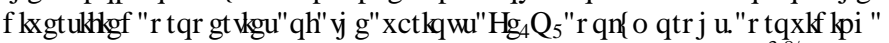

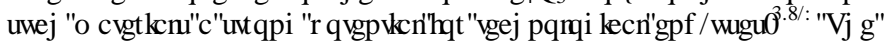

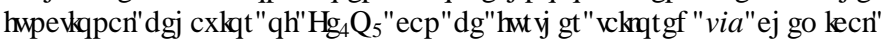

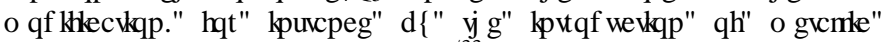

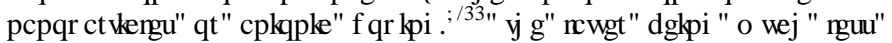
H SORUHW, Q SDWNXOU IOXRUQH GRSIQ ILW WXH IRFXV RIDDQ IQMQM

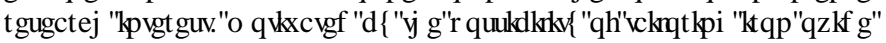

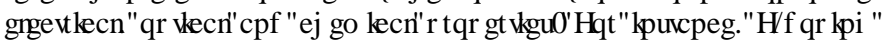

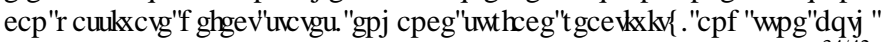

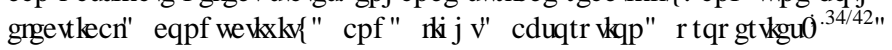

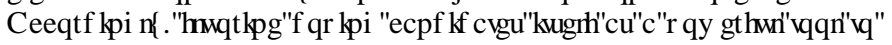
IP SLRYH WXH X WMP IEHDMIRUIQ VMHDODSSCFDARQVHQRRP SDMQ $\square$

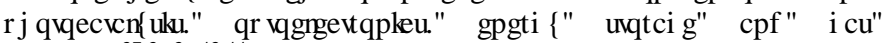

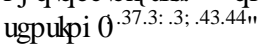

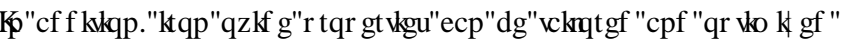

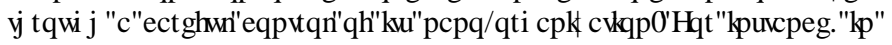
YIHZ $\square$ RI HMHWDO SKRLRFDMD WFSSKRWRHOFWRFKH IFDO XWD] DARQV]

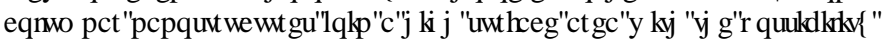

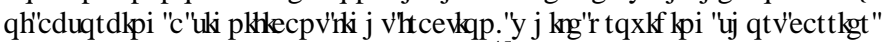

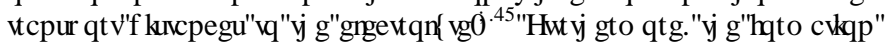

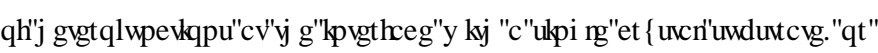
Z LWXD VFRQGQDORWWFWXHGP DMUDOFDQ WXSSHMUUFRP EIQDARQ

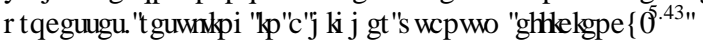

2 Q WRV EDMV KHHQ Z H USRUWRQ WXH W QMKHMV DOQG FKP IFR]

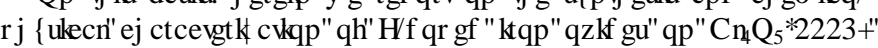

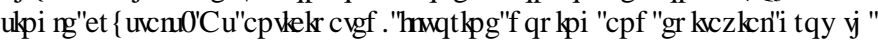

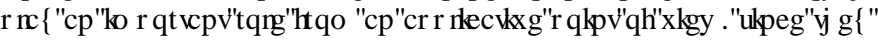
GIHFOI IP SDFW WXH P DMUD IXQFWRQD EHWMRU 1 RQHMHOMU

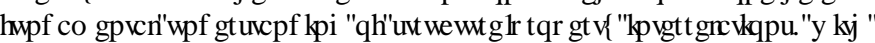

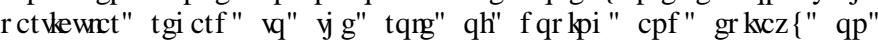

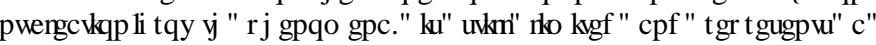

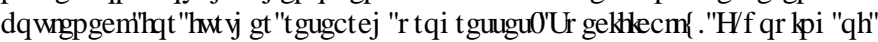

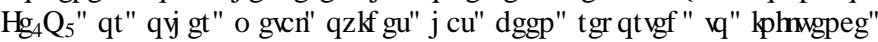

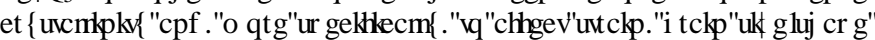
DQGJ IRZ WN RUHQMWRQ

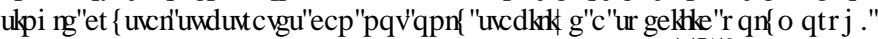

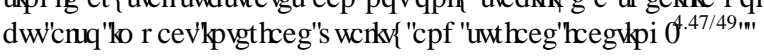

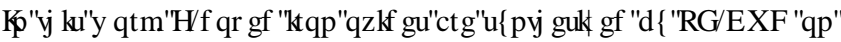

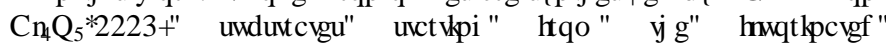

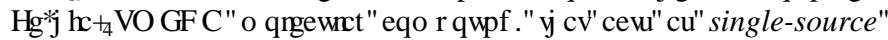
SUFXURU IRU ERW ) H DQG ) प 6SHFIDO DWWQRQ Z DV GHRWG UR D

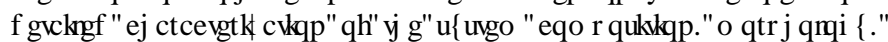

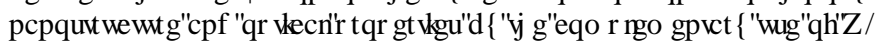

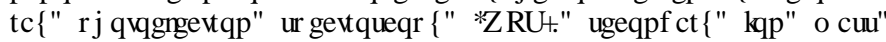

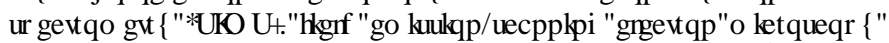

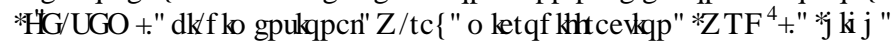

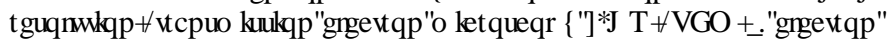

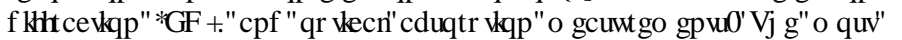

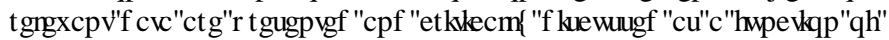
SUSDDUMHFRQCWRQVU 


\section{Experimental section}

\section{Synthesis}

The $\mathrm{Fe}(\mathrm{hfa})_{2}$ TMEDA precursor was synthesized following a previously reported literature procedure. ${ }^{28} \mathrm{Al}_{2} \mathrm{O}_{3}(0001)$ single crystals $\left(10 \times 10 \times 1 \mathrm{~mm}^{3}\right.$, one-side polished) were purchased from Crystal GmbH (Berlin, Germany) and used as growth substrates without any further treatment. Deposition experiments were carried out using a two electrode radio frequency (RF; $v=13.56 \mathrm{MHz}) \mathrm{PE}-$ CVD apparatus $^{29}$ in $\mathrm{Ar} / \mathrm{O}_{2}$ (gas flow rates $=15$ and $20 \mathrm{sccm}$, respectively) plasmas. The total pressure, deposition time and RF power were kept constant at $1.0 \mathrm{mbar}, 60 \mathrm{~min}$ and $10 \mathrm{~W}$, respectively, using an interelectrode distance of $6.0 \mathrm{~cm}$. $\mathrm{Fe}(\mathrm{hfa})_{2} \mathrm{TMEDA}$ was vaporized at $65^{\circ} \mathrm{C}$ by means of an oil bath, and its vapors were transported into the reaction chamber by means of an Ar flow (rate $=60 \mathrm{sccm}$ ). The feeding gas lines were heated at $140^{\circ} \mathrm{C}$ to prevent precursor condensation phenomena. Under the above processing conditions, experiments were carried out at 200 , 300 and $400^{\circ} \mathrm{C}$ to investigate the influence of growth temperature on the properties of the resulting iron oxide-based deposits.

\section{Characterization}

XPS analyses were performed on a Perkin-Elmer $\Phi$ 5600ci spectrometer, using a standard $\mathrm{AlK} \alpha$ excitation source $(1486.6 \mathrm{eV})$, at working pressures lower than $10^{-8}$ mbar. Binding energies (BEs, standard deviation $= \pm 0.2 \mathrm{eV}$ ) were corrected for charging assigning a value of $284.8 \mathrm{eV}$ to the adventitious $\mathrm{C} 1 \mathrm{~s}$ line. ${ }^{30} \mathrm{Ar}^{+}$sputtering was carried out at $3.0 \mathrm{kV}\left(\right.$ area $=2 \times 2 \mathrm{~mm}^{2}$, Ar partial pressure $=5 \times 10^{-8}$ mbar). Atomic percentages (at. \%) were calculated by signal integration using standard PHI V5.4A sensitivity factors. Peak fitting was performed by a least-squares procedure, adopting GaussianLorentzian peak shapes.

SIMS analyses were carried out by means of an IMS $4 \mathrm{f}$ mass spectrometer (Cameca) using a $14.5 \mathrm{KeV} \mathrm{Cs}^{+}$primary beam (current $=25 \mathrm{nA}$, stability $=0.3 \%$ ) and by negative secondary ion detection, adopting an electron gun for charge compensation. Beam blanking mode and high mass resolution configuration were adopted. Signals were recorded rastering over an area of $175 \times 175 \mu \mathrm{m}^{2}$ and detecting secondary ions from a sub-region close to $8 \times 8 \mu \mathrm{m}^{2}$ in order to avoid crater effects.

FE-SEM micrographs were collected by a Zeiss SUPRA 40VP instrument, with a primary beam voltage of $10 \mathrm{kV}$. The mean nanoaggregate size was evaluated through the SmartSEM ${ }^{\circledR}$ software by averaging over 20 independent measurements for each specimen.

$\mathrm{XRD}^{2}$ images were collected by a Dymax-RAPID X-ray microdiffractometer with a cylindrical imaging plate detector, that allows collecting diffraction data in the ranges $2 \theta=0-160^{\circ}$ (horizontally) and $2 \theta=-45-+45^{\circ}$ (vertically) upon using $\mathrm{CuK} \alpha$ radiation. The incident beam collimators enable different spot sizes to be projected onto the sample. In this work, measurements were performed in reflection mode, adopting a collimator diameter of 300 $\mu \mathrm{m}$ and an exposure time of $30 \mathrm{~min}$ for each $\mathrm{XRD}^{2}$ pattern.

(HR)-TEM and ED experiments were carried out on a FEI Tecnai G2 30 UT microscope operated at $300 \mathrm{kV}$. High-angle annular darkfield STEM (HAADF-STEM) experiments were performed by an aberration-corrected Titan "cubed" microscope, operated at $300 \mathrm{kV}$. The used convergence semi-angle $\alpha$ and HAADF detector inner semi-angle $\beta$ were 21 and $50 \mathrm{mrad}$, respectively. Specimens for cross-sectional (CS) and plane-view (PV) observations were prepared by mechanical polishing down to a thickness of approximately $20 \mu \mathrm{m}$, followed by $\mathrm{Ar}^{+}$ion milling under grazing angle down to electron transparency.

Optical absorption spectra were recorded by means of a Cary $5 \mathrm{E}$
(Varian) dual-beam spectrophotometer with a spectral bandwidth of $1 \mathrm{~nm}$, operating in transmission mode at normal incidence. For each spectrum, the substrate contribution was subtracted. Optical bandgaps were estimated from Tauc plots $(\alpha h v)^{2} v s . h v .^{5,18,31}$

\section{Results and Discussion}

\section{Composition}

In order to investigate the system surface and in-depth composition, XPS analyses were preliminarily carried out. Irrespective of the synthesis conditions, all samples were characterized by the presence of iron, oxygen, fluorine and carbon, the latter being limited to the outermost deposit layers. Fig. 1a displays the Fe2p surface peak for an iron oxide sample grown at $300^{\circ} \mathrm{C}$. The $\mathrm{Fe} 2 \mathrm{p}_{3 / 2}$ signal was located at a $\mathrm{BE}$ of $711.0 \mathrm{eV}$ with a spin-orbit separation of $13.5 \mathrm{eV}$. These data, along with the low intensity of shake-up satellites, are in good agreement with the presence of iron(III) oxide free from other $\mathrm{Fe}$ containing species. ${ }^{10,11,32-35}$ Accordingly, the main contribution to the O1s peak (see Fig. 1b, component I, $85.6 \%$ of the overall $\mathrm{O}$ signal) at $530.1 \mathrm{eV}$ was attributed to lattice oxygen in $\mathrm{Fe}_{2} \mathrm{O}_{3}{ }^{26,32,35,36}$ The second band (component II) located at $\mathrm{BE}=531.9 \mathrm{eV}$ could be ascribed to adsorbed - $\mathrm{OH}$ groups and carbonates species arising from atmospheric exposure. ${ }^{32,33}$
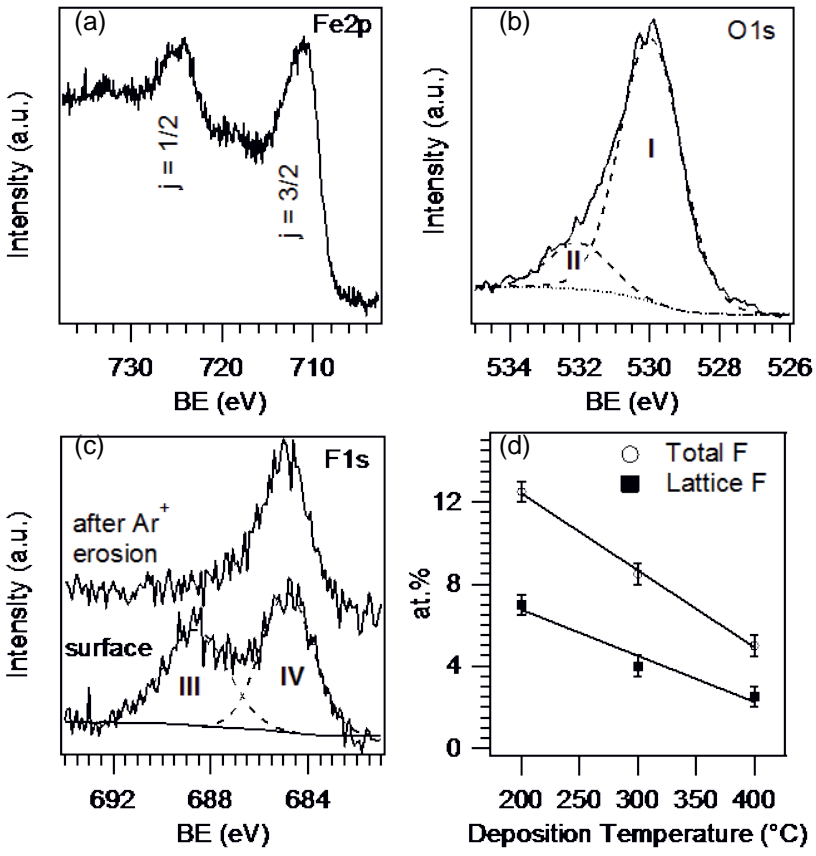

Fig. 1 Core-level photoelectron peaks for a specimen synthesized at $300^{\circ} \mathrm{C}$ : (a) $\mathrm{Fe} 2 \mathrm{p}$, (b) $\mathrm{O} 1 \mathrm{~s}$, (c) $\mathrm{F} 1 \mathrm{~s}$ (before and after $5^{\prime} \mathrm{Ar}^{+}$sputtering). (d) Dependence of fluorine surface content on deposition temperature.

As can be observed, the F1s surface peak could be decomposed by means of two bands (Fig. 1c). Whereas the high $\mathrm{BE}$ one (component III, BE $=688.5 \mathrm{eV}$ ) was due to $\mathrm{CF}_{\mathrm{x}}$ species arising from an incomplete precursor decomposition, ${ }^{10,33,37,38}$ component IV at $684.8 \mathrm{eV}$ was traced back to $\mathrm{F}$ incorporation into iron oxide lattice, ${ }^{7,10,32,38}$ indicating the formation of $\mathrm{F}$-doped $\mathrm{Fe}_{2} \mathrm{O}_{3}$. Interestingly, the former signal disappeared upon a mild sputtering, highlighting that the presence of $\mathrm{CF}_{\mathrm{x}}$ moieties was limited to the outermost layers. Conversely, lattice fluorine was still clearly detectable after $\mathrm{Ar}^{+}$ erosion (Fig. 1c). It is also worth noting that both the overall and lattice $F$ surface content underwent a linear decrease upon increasing the deposition temperature (Fig. 1d), as already 
observed under similar conditions. ${ }^{9,39}$

In order to investigate the fluorine distribution in the inner material layers, XPS and SIMS depth profiling were carried out (Fig. 2). Fig. 2a shows a representative XPS depth profile. The slight decrease of oxygen at. \% occurring after the first $15 \mathrm{~min}$ of erosion is likely due to preferential sputtering phenomena, responsible also for the apparent increase of iron content. ${ }^{30}$ Fluorine amount progressively decreased during the first erosion cycles and subsequently reached a constant value of $c a .2$ at. \% in the inner sample region. This behavior was related to the disappearance of surface $C F_{x}$ species upon erosion, resulting in the presence of the sole lattice fluorine, that was homogeneously distributed in the iron oxide matrix.
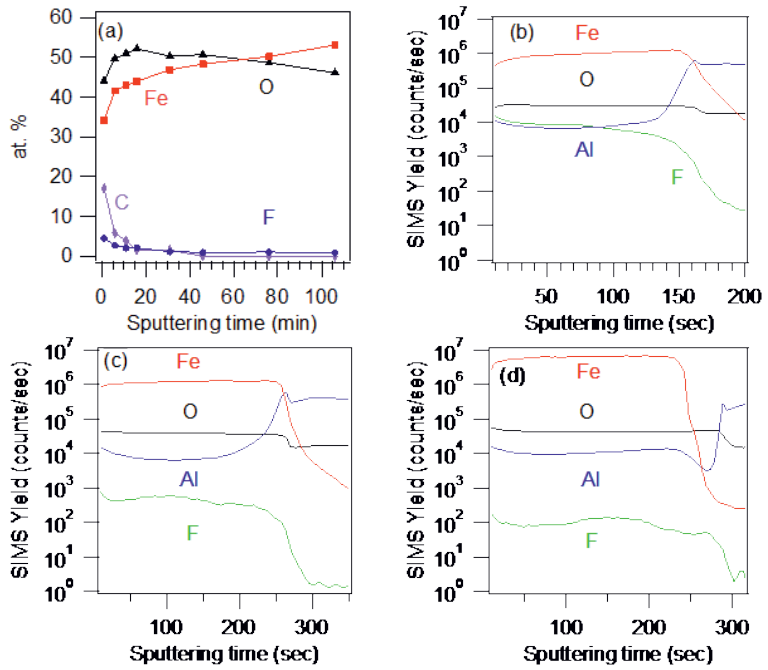

Fig. 2 (a) XPS depth profile for a sample deposited at $300^{\circ} \mathrm{C}$. SIMS profiles for specimens grown at (b) $200^{\circ} \mathrm{C}$, (c) $300^{\circ} \mathrm{C}$ and (d) $400^{\circ} \mathrm{C}$.

The results of SIMS analyses (Figs. 2b-d) agreed to a good extent with XPS ones. In particular, irrespective of the adopted growth temperature, $\mathrm{Fe}, \mathrm{O}$ and $\mathrm{F}$ ionic yield profiles were almost parallel throughout the entire nanodeposit thickness, indicating an uniform chemical composition and an even doping level. In addition, all samples showed a sharp and well defined interface with the substrate, allowing an accurate calculation of the deposit thickness. The pertaining values were $200 \pm 15,260 \pm 15$, and $170 \pm 15 \mathrm{~nm}$ at 200 , 300 and $400^{\circ} \mathrm{C}$, respectively.

\section{Morphology}

The influence of processing conditions on the system morphology was analyzed by FE-SEM (Fig. 3). At $200^{\circ} \mathrm{C}$, plane-view investigation evidenced the formation of leaf-like lamellar nanostructures with an average lateral size and thickness of 80 and $25 \mathrm{~nm}$, respectively. As evidenced by a closer micrograph inspection, such structures were composed by smaller and randomly oriented interconnected particles, suggesting the occurrence of a polycrystalline material.

Upon increasing the growth temperature to $300^{\circ} \mathrm{C}$, the deposit morphology was only partially reminiscent of the previous one. In fact, the observed lamellar structures exhibited a more pronounced faceting and, in some cases, a well evident rectangular prism habit, with an in-plane size of $120 \mathrm{~nm} \times 70 \mathrm{~nm}$.

At $400^{\circ} \mathrm{C}$, the system morphology underwent significant variations with respect to the previous cases. In fact, homogeneously distributed columnar structures aligned perpendicularly to the substrate surface could be observed. These nano-columns were characterized by displayed faceted tips, with average diameter and length values of 30 and $170 \mathrm{~nm}$, respectively. The obtainment of this nano-organization at the highest deposition temperature suggested a marked influence of the $\mathrm{Al}_{2} \mathrm{O}_{3}(0001)$ substrate on $\mathrm{Fe}_{2} \mathrm{O}_{3}$ nucleation and growth, as discussed in detail below.
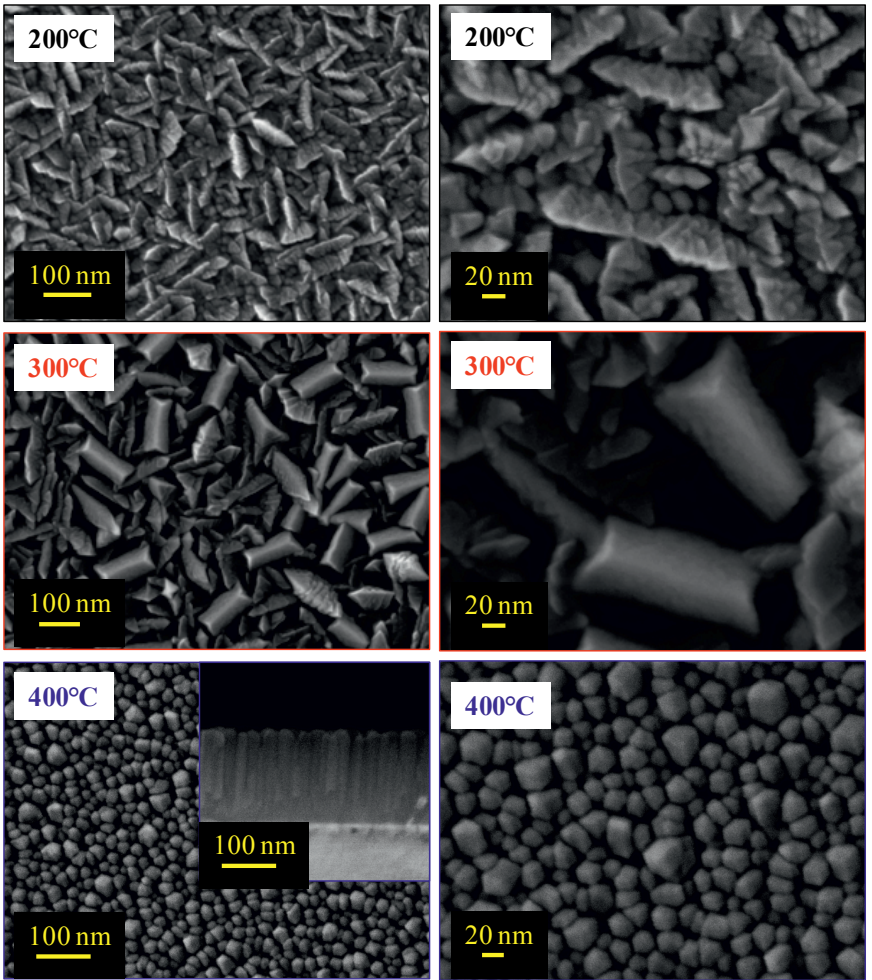

Fig. 3 FE-SEM PV micrographs of the iron oxide materials. The inset shows a cross-sectional image of the $400^{\circ} \mathrm{C}$ sample.
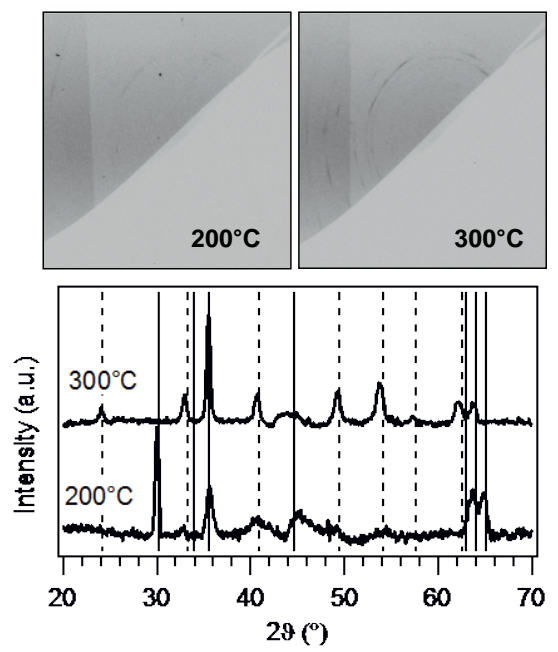

Fig. $4 \mathrm{XRD}^{2}$ maps and corresponding integrated spectra of specimens obtained at 200 and $300^{\circ} \mathrm{C}$. Reflections expected for $\gamma-\mathrm{Fe}_{2} \mathrm{O}_{3}{ }^{40}$ and $\alpha$ $\mathrm{Fe}_{2} \mathrm{O}_{3}{ }^{41}$ are marked by continuous and dashed lines, respectively.

\section{Structure}

The microstructural properties of the $\mathrm{Fe}_{2} \mathrm{O}_{3}$ nanomaterials were analyzed by two-dimensional X-ray diffraction and the pertaining $\mathrm{XRD}^{2}$ maps are reported in Fig. 4, along with the corresponding integrated patterns. At the lowest deposition temperature $\left(200^{\circ} \mathrm{C}\right)$, signals at $2 \vartheta=30.0,35.6,63.7$ and $65.0^{\circ}$ were detected, and attributed to the (220), (311), (441) and (530) reflections of $\gamma-\mathrm{Fe}_{2} \mathrm{O}_{3}$ 
(maghemite). ${ }^{40}$ On the other hand, the specimen deposited at $300^{\circ} \mathrm{C}$ displayed peaks at $24.1,33.0,35.5,40.7,49.2,53.8,57.3,62.2,63.6$ and $74.9^{\circ}$, attributable to the (012), (104), (110), (113), (024), (116), (018), (214), (300) and (220) reflections of $\alpha-\mathrm{Fe}_{2} \mathrm{O}_{3}$ (hematite). ${ }^{41}$ In this case, a comparison with the powder reference spectrum indicated a preferred orientation along the $<110\rangle$ direction. The observed phase transition from maghemite $\left(200^{\circ} \mathrm{C}\right)$ to hematite $\left(300^{\circ} \mathrm{C}\right)$ was not surprising, and could be explained by the higher thermodynamic stability of $\alpha-\mathrm{Fe}_{2} \mathrm{O}_{3}$.

Nevertheless, at $400^{\circ} \mathrm{C}$ no reflections other than the substrate ones could be appreciated in the $\mathrm{XRD}^{2}$ pattern (not reported). A similar finding suggests the occurrence of an epitaxial/oriented growth strongly affected by the underlying $\mathrm{Al}_{2} \mathrm{O}_{3}(0001)$ support since, in a similar case, a full overlap between the substrate and the deposit reflections is expected. ${ }^{42}$

In order to attain a deeper insight into this phenomenon, a detailed TEM analysis was carried out on the sample synthesized at $400^{\circ} \mathrm{C}$. Low-magnification and high resolution PV and CS TEM images of the specimen, together with representative ED patterns taken from different sample areas, are displayed in Fig. 5.

PV observations indicated that individual grains had a pseudohexagonal morphology (see Fig. 5a), with typical diameters of nearly $40 \mathrm{~nm}$. The PV HR-TEM image in Fig. 5b unambiguously confirmed the grain hexagonal structure, with predominantly exposed (-1010), (1-100) and (0-110) facets. Furthermore, CS data (Fig. 5c) evidenced an epitaxial, columnar, $c$-oriented hematite growth, with the following relationship: [0001] $\alpha-\mathrm{Fe}_{2} \mathrm{O}_{3} / /$ [0001] $\mathrm{Al}_{2} \mathrm{O}_{3}$ and (01-10) $\alpha-\mathrm{Fe}_{2} \mathrm{O}_{3} / /(01-10) \mathrm{Al}_{2} \mathrm{O}_{3}$.
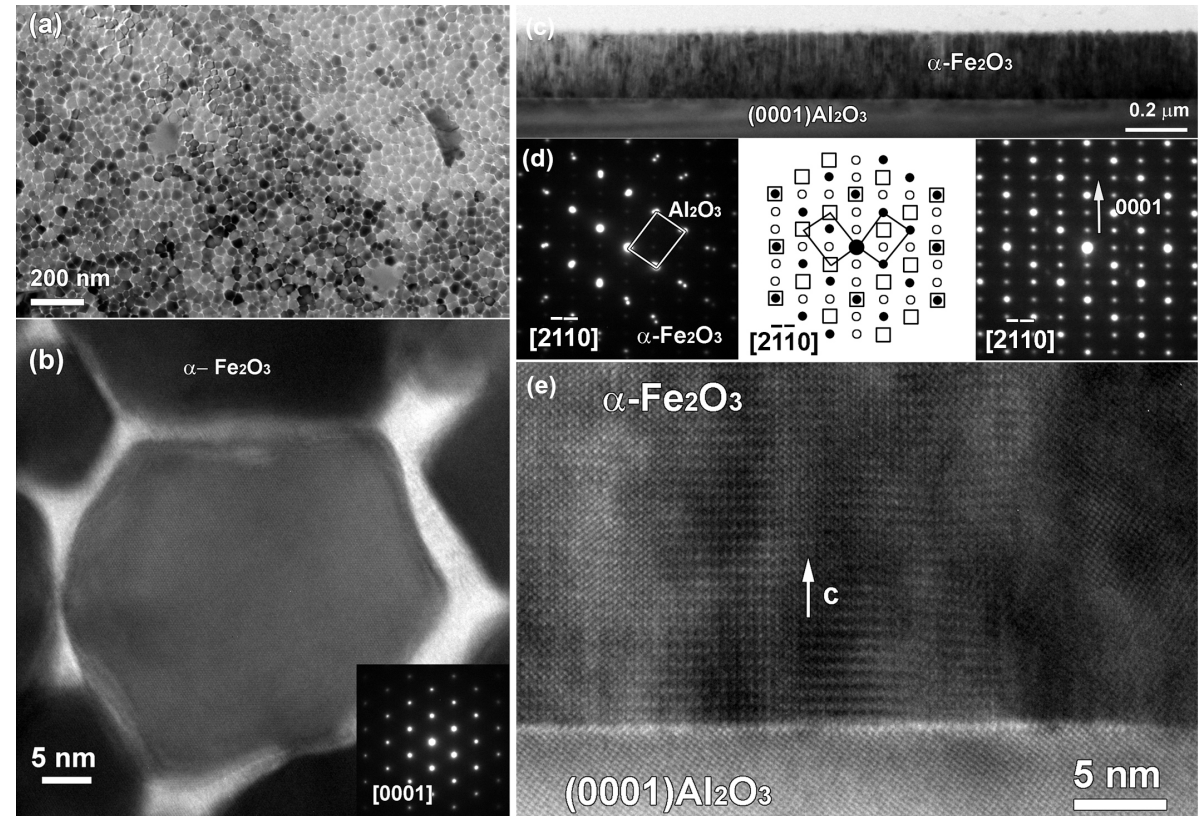

Fig. 5 (a) Low-magnification PV TEM image of the $\alpha-\mathrm{Fe}_{2} \mathrm{O}_{3}$ sample deposited at $400^{\circ} \mathrm{C}$. (b) PV HR-TEM image of the same specimen, with the corresponding ED pattern as inset. The grains are $c$-oriented and are imaged along the [0001] zone axis for $\alpha-\mathrm{Fe}_{2} \mathrm{O}_{3}$. (c) Low-magnification CS TEM image of $\alpha-\mathrm{Fe}_{2} \mathrm{O}_{3}$ on $\mathrm{Al}_{2} \mathrm{O}_{3}$ (0001). (d) Two selected CS ED patterns recorded in different areas, indicating the presence of hematite (left) and of a twinned structure (right). In the middle, a schematic drawing of the twinned structure, taking into account twinning over $\{01-10\}$ type planes, combined with double diffraction, is presented. (e) HR-TEM image of a twinned $\alpha-\mathrm{Fe}_{2} \mathrm{O}_{3}$ region.

The ED pattern in Fig. 5d left, imaged along the [2-1-10] zone axis orientation, is a superposition of the deposit and substrate structure, where the crystal phase of the former can be indexed using the space group and unit cell parameters of $\alpha$ $\mathrm{Fe}_{2} \mathrm{O}_{3}[a=0.503 \mathrm{~nm}, c=1.374 \mathrm{~nm}$, rhombohedral $R 3-$ $c(167)] .^{2,35,43-45}$ Nevertheless, several ED images exhibited a more complex pattern, with various superstructure spots (compare Fig. 5d, right). A CS HR-TEM image taken from such a region is shown in Fig. 5e. The observed HR-TEM contrast and ED data can be likely traced back to the presence of regular twinnings within the $\alpha-\mathrm{Fe}_{2} \mathrm{O}_{3}$ phase. A schematic view of the right-hand ED pattern, taking into account a twin structure over the (2-1-10) plane, is displayed in the central panel of Fig. 5d, where dots and squares correspond to two different $\alpha-\mathrm{Fe}_{2} \mathrm{O}_{3}$ orientations sharing a common (0001) plane, whereas empty circles represent spots attributable to double diffraction phenomena.

PV and CS TEM data suggest $c$-oriented, randomly distributed grains with two different orientation variants $A$ and $\mathrm{B}$, related to each other by a $60^{\circ}$ rotation along the [0001] axis. A model for such a kind of growth is presented in Fig. 6.
According to the proposed model, the difference between the two possibilities can be detected only in CS observations. Indeed, when the twin variants overlap, the structure observed in HR-TEM and ED patterns is expected to appear. Conversely, in the case of PV imaging, this rotation cannot be detected (see the top panel in Fig. 6).

In order to confirm the proposed twinned growth, HAADFSTEM imaging of the interface region was carried out. HAADF-STEM is mass-thickness sensitive, having image contrast that scales with the atomic number $Z^{\sim 1.7}$. Since it is an incoherent imaging technique, diffraction contrast will not hinder the interpretation of the images, like in the case of HRTEM. Fig. 7 shows representative high resolution HAADFSTEM images of a twinned area (Fig. 7a) and twin boundary (Fig. 7b). The structure models are overlaid, and match perfectly with the acquired images, confirming thus the validity of the proposed twinning model. 


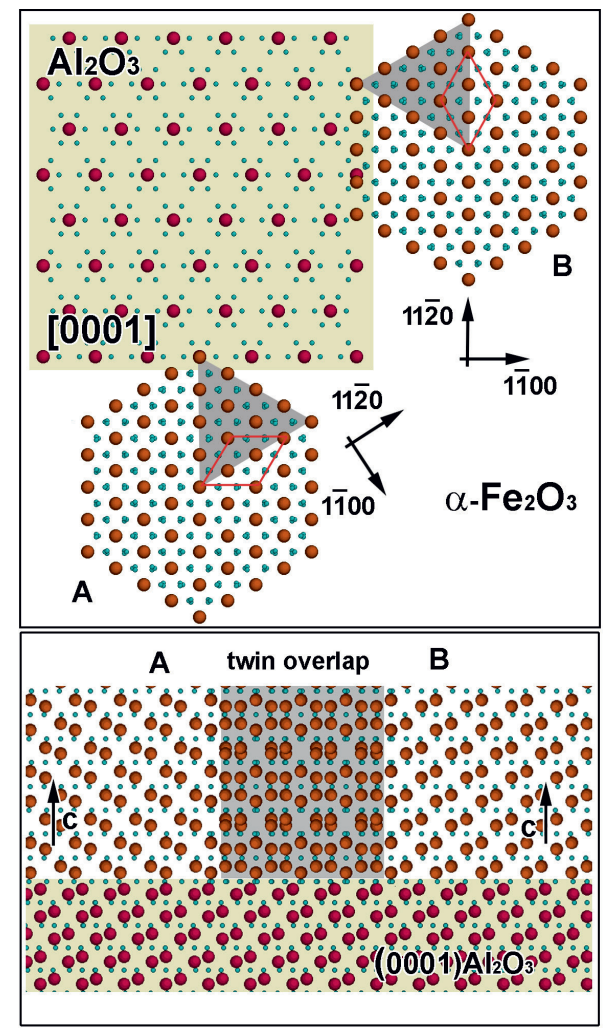

Fig. 6 Atomic model of $\alpha-\mathrm{Fe}_{2} \mathrm{O}_{3}$, grown epitaxially on $\mathrm{Al}_{2} \mathrm{O}_{3}$ (0001), presented in two orthogonal view directions corresponding to PV (top) and CS (bottom) TEM observations.

\section{Optical properties}

Special attention was finally devoted to investigating the combined influence of F-doping and morphology/phase composition on the system optical properties, in order to better evaluate the suitability of the above materials for eventual optoelectronic or photocatalytic applications. In particular, as also reported for other metal oxides, oxygen replacement by fluorine can shift the absorption edge, affect the recombination between photogenerated electrons and holes, passivate defect states, and impact the system resistivity modifying carrier concentration and mobility., 9,11,12-16,19-21,38

Fig. 8 displays the optical absorption spectra of iron oxidebased deposits grown at different temperatures. As can be observed, all specimens show a strong absorption for wavelengths lower than $600 \mathrm{~nm}$, responsible for their red-toyellow color. ${ }^{46-48}$ Under the assumption of a direct allowed transition, the following band-gap values were derived from Tauc plots in Fig. 8: $2.52 \mathrm{eV}, 2.22 \mathrm{eV}$ and $2.16 \mathrm{eV}$ for specimens grown at 200,300 and $400^{\circ} \mathrm{C}$, respectively. These values are significantly blue-shifted with respect to literature data for iron(III) oxides, that are typically close to $2.0 \mathrm{eV}$. $^{5,46,49}$ A similar finding suggests that, beside phase composition, even other parameters appreciably affect the system optical properties. More specifically, the obtainment of band-gap values appreciably higher than literature ones can be traced back to a modified carrier concentration in $\mathrm{Fe}_{2} \mathrm{O}_{3}$ conduction/valence bands when oxygen vacancies are saturated by fluorine. ${ }^{9,19,20,50}$ This explanation also accounts for the progressive increase of band-gap values at the lowest deposition temperatures that, according to Figs. 1 and 2, result in a higher F-content in the obtained systems.

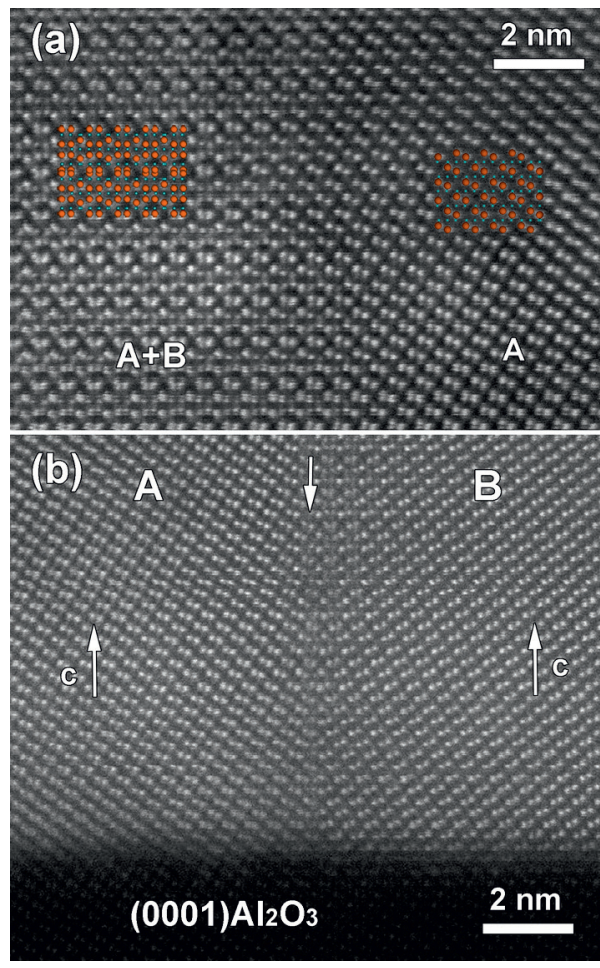

Fig. $7 \mathrm{CS}$ high resolution HAADF-STEM images along the [2-1-10] zone axis orientation of: (a) a twinned $\alpha-\mathrm{Fe}_{2} \mathrm{O}_{3}$ region $(\mathrm{A}+\mathrm{B})$ next to a region of simple $\alpha-\mathrm{Fe}_{2} \mathrm{O}_{3}(\mathrm{~A})$; (b) a twin boundary in $\alpha-\mathrm{Fe}_{2} \mathrm{O}_{3}$ (central arrow) showing the superstructure contrast in the boundary region.

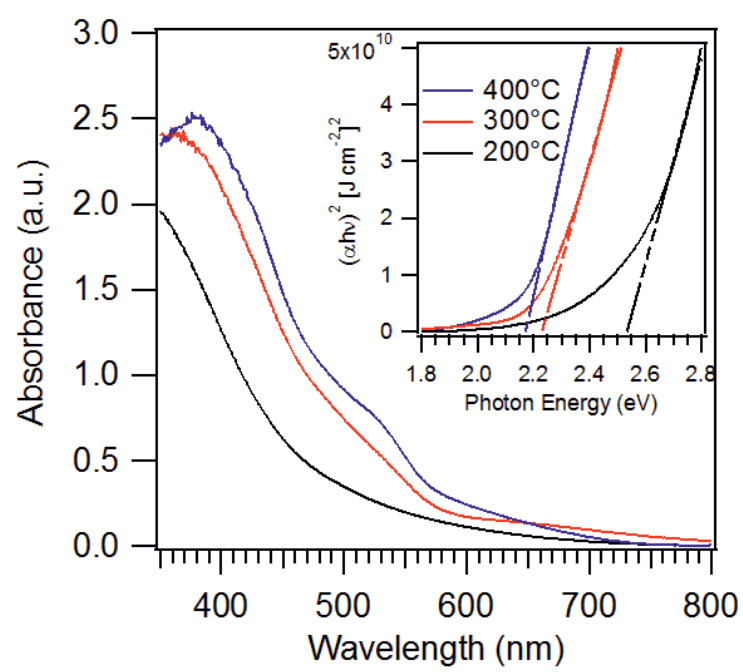

Fig. 8 Optical absorption spectra of iron oxide samples grown at 200, 300 and $400^{\circ} \mathrm{C}$. The inset displays the corresponding Tauc plots.

\section{Conclusions}

A PE-CVD approach to $\mathrm{Fe}_{2} \mathrm{O}_{3}$-based nanostructures on $\mathrm{Al}_{2} \mathrm{O}_{3}(0001)$ single crystal substrates has been reported. The obtained iron oxide nanomaterials were in-situ doped with fluorine thanks to the use of a fluorinated molecular compound, Fe(hfa $)_{2}$ TMEDA, acting as a single-source precursor for both $\mathrm{Fe}$ and $\mathrm{F}$. Controlled variations of the deposition temperature directly impacted both the system chemical composition and crystalline phase. In particular, a $\gamma-\mathrm{Fe}_{2} \mathrm{O}_{3}$ to $\alpha-\mathrm{Fe}_{2} \mathrm{O}_{3}$ phase transition was observed upon going from 200 to 
$300^{\circ} \mathrm{C}$, whereas highly oriented hematite nanocolumns were epitaxially grown at $400^{\circ} \mathrm{C}$. A detailed structural and morphological investigation enabled to obtain a deep insight on the interrelations between processing parameters and composition, structure/morphology and optical properties of the target systems. The proposed fabrication process paves the way to the development of iron oxide nanosystems for various applications, in particular in the fields of optoelectronics and photocatalysis, for which control of fluorine content, nano-organization, and optical properties is expected to result in a parallel tuning of functional performances. Further developments of the current research will concern the influence of F-doping on the magnetic properties of $\mathrm{Fe}_{2} \mathrm{O}_{3}$. Following our recent paper on the magnetic behavior of $\beta$ - and $\varepsilon$ $\mathrm{Fe}_{2} \mathrm{O}_{3}$, fir future efforts will be specifically focused on the investigation of $\mathrm{F}$-doped $\alpha$ - and $\gamma-\mathrm{Fe}_{2} \mathrm{O}_{3}$.

\section{Acknowledgements}

The authors kindly acknowledge the financial support under the FP7 project "SOLAROGENIX" (NMP4-SL-2012-310333) as well as from Padova University ex-60\% 2012-2013-2014, grant $\mathrm{n}^{\circ} \mathrm{CPDR} 132937 / 13$ (SOLLEONE), and Regione Lombardia-INSTM ATLANTE projects. Thanks are also due to Dr. D. Bekermann (Padova University, Italy) for technical and synthetic assistance. S.T. gratefully acknowledges the FWO for a post-doctoral fellowship and for project number G004613N. This work was supported by funding from the European Research Council under the Seventh Framework Program (FP7), ERC grant N²46791 - COUNTATOMS

\section{Notes and references}

${ }^{a}$ Department of Chemistry, Padova University and INSTM, 35131 Padova, Italy.

${ }^{b}$ Chemistry for Technologies Laboratory, University of Brescia, 25123 Brescia, Italy.

${ }^{c}$ Laboratoire CRISMAT, UMR 6508, CNRS-ENSICAEN, 14050 Caen Cedex 4, France.

d Department of Physics and Astronomy, Padova University, 35131 Padova, Italy.

${ }^{e}$ EMAT, Antwerp University, 2020 Antwerpen, Belgium.

${ }^{f}$ IENI-CNR and INSTM, Department of Chemistry, Padova University, 35131 Padova, Italy.

1. L. Machala, J. Tuček and R. Zbořil, Chem. Mater., 2011, 23, 3255.

2. M. Lubbe, A. M. Gigler, R. W. Stark and W. Moritz, Surf. Sci., 2010, 604, 679 .

3. D. Barreca, G. Carraro, A. Gasparotto, C. Maccato, F. Rossi, G. Salviati, M. Tallarida, C. Das, F. Fresno, D. Korte, U. Lavrenčič Štangar, M. Franko and D. Schmeisser, ACS Appl. Mater. Interfaces, 2013, 5, 7130 .

4. G. Carraro, C. Maccato, A. Gasparotto, T. Montini, S. Turner, O. I. Lebedev, V. Gombac, G. Adami, G. Van Tendeloo, D. Barreca and P. Fornasiero, Adv. Funct. Mater., 2014, 24, 372.

5. J. D. Desai, H. M. Pathan, S. K. Min, K. D. Jung and O. S. Joo, Appl. Surf. Sci., 2006, 252, 2251.

6. P. Tartaj, M. P. Morales, T. Gonzalez-Carreño, S. VeintemillasVerdaguer and C. J. Serna, Adv. Mater., 2011, 23, 5243.

7. B. L. Lv, Z. Y. Liu, H. Tian, Y. Xu, D. Wu and Y. H. Sun, Adv. Funct. Mater., 2010, 20, 3987.

8. K. Karthikeyan, S. Amaresh, S. N. Lee, V. Aravindan and Y. S. Lee, Chem. Asian J., 2014, 9, 852.

9. D. Barreca, G. Carraro, A. Gasparotto, C. Maccato, C. Sada, A. P. Singh, S. Mathur, A. Mettenbörger, E. Bontempi and L. E. Depero,
Int. J. Hydrogen Energy, 2013, 38, 14189.

10. G. Carraro, D. Barreca, D. Bekermann, T. Montini, A. Gasparotto, V. Gombac, C. Maccato and P. Fornasiero, J. Nanosci. Nanotechnol., 2013, 13, 4962.

11. G. Carraro, D. Barreca, E. Comini, A. Gasparotto, C. Maccato, C. Sada and G. Sberveglieri, CrystEngComm, 2012, 14, 6469.

12. H. Seo, L. R. Baker, A. Hervier, J. Kim, J. L. Whitten and G. A. Somorjai, Nano Lett., 2011, 11, 751.

13. A. Gasparotto, D. Barreca, D. Bekermann, A. Devi, R. A. Fischer, P. Fornasiero, V. Gombac, O. I. Lebedev, C. Maccato, T. Montini, G. Van Tendeloo and E. Tondello, J. Am. Chem. Soc., 2011, 133, 19362.

14. C. O'Keeffe, P. Gannon, P. Gilson, A. Kafizas, I. P. Parkin and R. Binions, Thin Solid Films, 2013, 537, 131.

15. Y.-J., Choi and H.-H. Park, J. Mater. Chem. C., 2014, $2,98$.

16. A. Kafizas, N. Noor, P. Carmichael, D. O. Scanlon, C. J. Carmalt and I. P. Parkin, Adv. Funct. Mater., 2014, 24, 1758.

17. H. F. Liang and R. G. Gordon, J. Mater. Sci., 2007, 42, 6388.

18. I. Akyuz, S. Kose, E. Ketenci, V. Bilgin and F. Atay, J. Alloys Compd., 2011, 509, 1947.

19. J. Santos-Cruz, G. Torres-Delgado, R. Castanedo-Perez, C. I. ZunigaRomero and O. Zelaya-Angel, Thin Solid Films, 2007, 515, 5381.

20. R. Gonzalez-Hernandez, A. I. Martinez, C. Falcony, A. A. Lopez, M. I. Pech-Canul and H. M. Hdz-Garcia, Mater. Lett., 2010, 64, 1493.

21. C.-1. Song, J. Wang, M.-1. Zeng, J.-q. Zhu, Y. Liu, G. Xu and G.-r. Han, J. Sol-Gel Sci. Technol., 2013, 68, 121.

22. X. Noirfalise, T. Godfroid, G. Guisbiers and R. Snyders, Acta Mater., 2011, 59, 7521.

23. N. S. Chaudhari, S. S. Warule, S. Muduli, B. B. Kale, S. Jouen, B. Lefez, B. Hannoyer and S. B. Ogale, Dalton Trans., 2011, 40, 8003.

24. M. Kul, A. S. Aybek, E. Turan, M. Zor and S. Irmak, Sol. Energy Mater. Sol. Cells, 2007, 91, 1927.

25. F. Bertram, C. Deiter, K. Pflaum, M. Suendorf, C. Otte and J. Wollschlager, J. Appl. Phys., 2011, 110, 102208.

26. T. Fujii, F. M. F. de Groot, G. A. Sawatzky, F. C. Voogt, T. Hibma and K. Okada, Phys. Rev. B, 1999, 59, 3195.

27. S. Maheswaran, S. Thevuthasan, F. Gao, V. Shutthanandan, C. M. Wang and R. J. Smith, Phys. Rev. B, 2005, 72, 7.

28. D. Barreca, G. Carraro, A. Devi, E. Fois, A. Gasparotto, R. Seraglia, C. Maccato, C. Sada, G. Tabacchi, E. Tondello, A. Venzo and M. Winter, Dalton Trans., 2012, 41, 149.

29. D. Barreca, A. Gasparotto, E. Tondello, C. Sada, S. Polizzi and A. Benedetti, Chem. Vap. Deposition, 2003, 9, 199.

30. D. Briggs and M. P. Seah, Practical Surface Analysis, Wiley, New York, 1990.

31. N. A. M. Barakat, J. Mater. Sci., 2012, 47, 6237.

32. G. Carraro, A. Gasparotto, C. Maccato and D Barreca, Surf. Sci. Spectra, 2013, 20, 9.

33. J. F. Moulder, W. F. Stickle, P. E. Sobol and K. D. Bomben, Handbook of X-ray Photoelectron Spectroscopy, Perkin Elmer Corporation, Eden Prairie, MN, USA, 1992.

34. P. Li, E. Y. Jiang and H. L. Bai, J. Phys. D, 2011, 44, 075003.

35. S. I. Yi, Y. Liang, S. Thevuthasan and S. A. Chambers, Surf. Science 1999, 443, 212.

36. Y. Gao, Y. J. Kim, S. A. Chambers and G. Bai, J. Vac. Sci. Technol. A, 1997, 15, 332.

37. P. F. Fulvio, S. S. Brown, J. Adcock, R. T. Mayes, B. K. Guo, X. G. 
Sun, S. M. Mahurin, G. M. Veith and S. Dai, Chem. Mater., 2011, 23 4420.

38. S. Sumitsawan, J. Cho, M. L. Sattler and R. B. Timmons, Environ. Sci. Technol., 2011, 45, 6970.

39. D. Barreca, D. Bekermann, E. Comini, A. Devi, R. A. Fischer, A. Gasparotto, M. Gavagnin, C. Maccato, C. Sada, G. Sberveglieri and E. Tondello, Sens. Actuators B, 2011, 160, 79.

40. Pattern n³9-1346, JCPDS, 2000.

41. Pattern n $33-0664$, JCPDS, 2000.

42. D. Barreca, A. Devi, R. A. Fischer, D. Bekermann, A. Gasparotto, M. Gavagnin, C. Maccato, E. Tondello, E. Bontempi, L. E. Depero and C. Sada, CrystEngComm, 2011, 13, 3670.

43. A. Barbier, O. Bezencenet, C. Mocuta, J. B. Moussy, H. Magnan, N. Jedrecy, M. J. Guittet and M. Gautier-Soyer, Mater. Sci. Eng. B, 2007, 144, 19.

44. C. M. Wang, S. Thevuthasan, F. Gao, D. E. McCready and S. A. Chambers, Thin Solid Films, 2002, 414, 31.

45. I. J. Lee, J. Y. Kim, C. Yu, C. H. Chang, M. K. Joo, Y. P. Lee, T. B. Hur and H. K. Kim, J. Vac. Sci. Technol., A, 2005, 23, 1450.

46. Y. P. He, Y. M. Miao, C. R. Li, S. Q. Wang, L. Cao, S. S. Xie, G. Z. Yang, B. S. Zou and C. Burda, Phys. Rev. B, 2005, 71, 125411.

47. D. M. Sherman and T. D. Waite, Am. Mineral., 1985, 70, 1262.

48. D. A. Wheeler, G. M. Wang, Y. C. Ling, Y. Li and J. Z. Zhang, Energy Environ. Sci., 2012, 5, 6682.

49. B. Gilbert, J. E. Katz, J. D. Denlinger, Y. D. Yin, R. Falcone and G. A. Waychunas, J. Phys. Chem. C, 2010, 114, 21994.

50. E. Burstein, Phys. Rev., 1954, 93, 632.

51. G. Carraro, D. Barreca, C. Maccato, E. Bontempi, L. E. Depero, César de Julián Fernández and A. Caneschi, CrystEngComm, 2013, 15, 1039. 